\title{
Non-papillary Percutaneous Puncture: A Safe Approach to Consider
}

\author{
Authors: \\ *Arman Tsaturyan,, Panagiotis Kallidonis, ${ }^{1}$ Evangelos Liatsikos, $1,2,3$ \\ 1. Department of Urology, University of Patras, Greece \\ 2. Department of Urology, Medical University of Vienna, Austria \\ 3. Institute for Urology and Reproductive Health, Sechenov University, Moscow, \\ Russia \\ *Correspondence to tsaturyanarman@yahoo.com \\ Disclosure: $\quad$ The authors have declared no conflicts of interest. \\ Received: $\quad 17.05 .21$ \\ Accepted: $\quad 14.07 .21$ \\ Keywords: $\quad$ Non-papillary puncture, papillary puncture, percutaneous nephrolithotomy (PCNL). \\ Citation: $\quad$ EMJ Urol. 2021;9[1]:91-94.
}

\begin{abstract}
Percutaneous nephrolithotomy ( $P C N L)$ is the 'gold standard' treatment modality for renal stones larger than $2 \mathrm{~cm}$. It can be also applied to manage smaller renal stones and large, impacted stones located in the proximal ureter. Nevertheless, even in experienced hands, the PCNL procedure is associated with the development of several complications. Despite the existing extensive research in this field, studies evaluating the effect of puncture site on perioperative bleeding are very few. In part, this can be explained by the dogma that the safest way to perform kidney puncture is through the renal papilla. In this paper, the authors summarise their experience of non-papillary PCNL and demonstrate this puncture technique for PCNL tract establishment.
\end{abstract}

\section{INTRODUCTION}

Percutaneous nephrolithotomy (PCNL) is the 'gold standard' treatment modality for renal stones larger than $2 \mathrm{~cm}$. It can be also applied to manage smaller renal stones and large, impacted stones located in the proximal ureter. Nevertheless, even in experienced hands, the PCNL procedure is associated with the development of several complications. Perioperative bleeding represents one of the serious complications and accounts for $7.8 \%$ of cases, of which significant bleeding requiring blood transfusion occurs in $5.7 \%$. $^{1}$ Due to this complication, many specialists still fear practising PCNL. To address the latter issue and reduce the rate of perioperative bleeding, technical refinements of surgical instruments

and surgical approaches have been proposed. ${ }^{2}$ Despite the existing extensive research in this field, studies evaluating the effect of puncture site on perioperative bleeding are very few. In part, this can be explained by the dogma that the safest way to perform kidney puncture is through the renal papilla. In this paper, the authors summarise their experience of non-papillary PCNL and demonstrate this puncture technique for PCNL tract establishment.

\section{DISCUSSION}

Successful kidney puncture and PCNL tract establishment are the initial and key steps of the procedure. Until recently, it was believed that papillary puncture through the papilla of the 
calyceal fornix is the only right and acceptable way to perform the puncture. The background for these beliefs were the anatomical studies by Sampaio et al. ${ }^{3}$ performed in the early 1990s. The authors demonstrated that fornical punctures were associated with a significantly lower rate of vascular injury. The punctures to the renal papilla, regardless of the punctured calyx, carried a 7-8\% probability of vessel injury, whereas punctures to the upper, middle, or lower infundibulum were associated with $67.6 \%, 61.5 \%$, and $68.2 \%$ vessel injuries, respectively. ${ }^{3}$

At first glance, those studies were ideal and did not leave any room for further research. In fact, until 2016-17 there was no literature discussing any alternative approach to papillary puncture, as this method was considered the safest and a must for practising specialists. However, those studies were associated with several limitations. All the punctures were performed on healthy cadaveric kidneys in an artificial environment. In the clinical setting, before puncturing the kidney, the needle passes through the skin subcutaneous tissue, muscles, and aponeurosis, and even best experimental settings could not replicate the accurate orientation of these structures. Urologists deal with patients with affected kidneys (urolithiasis, chronic pyelonephritis, dilated system). As such, the effect of those conditions was not evaluated. Moreover, puncture and tract dilation are two separate interventions, and one cannot conclude about tract dilation outcomes considering only findings of puncture studies.

In real life, the patients' anatomy may differ from the ideal, and performing a papillary puncture may not be feasible in all cases (Figure 1). The authors' initial experience for treating these patients showed that there was no increased risk of perioperative bleeding, while the performance of non-papillary puncture shortened and made the kidney puncture and subsequent tract establishment easier compared to standard papillary approach. With an increasing number of patients, the authors performed a retrospective observation of their results to objectively evaluate the outcomes. Out of the studied 137 patients, serious bleeding requiring blood transfusion occurred in only four patients (2.9\%), all of them treated conservatively. ${ }^{4}$

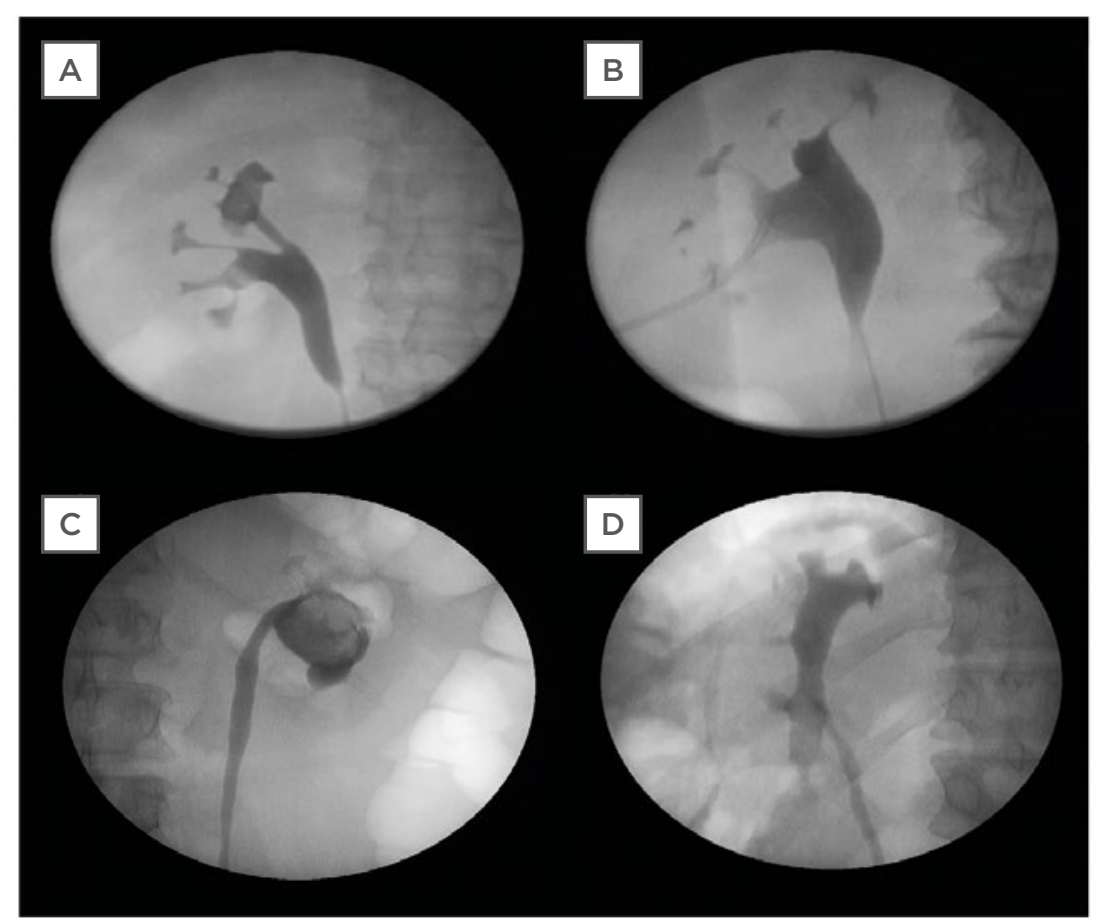

Figure 1: When performing a papillary puncture might not be feasible in patients.

A) Stone in the upper calyx with small papilla. B) Stone in the pelvis with narrow renal infundibula. C) Stone occupying the entire collecting system (calyces are not visualised). D) Stone located in the pelvis and lower calyx of the malrotated kidney. 
Table 1: The outcomes of studies performed on non-papillary percutaneous nephrolithotomy.

\begin{tabular}{|l|l|l|l|l|l|l|l|}
\hline Author & Year & $\begin{array}{l}\text { Study } \\
\text { population }\end{array}$ & $\begin{array}{l}\text { Access } \\
\text { size (Fr) }\end{array}$ & $\begin{array}{l}\text { Stone size } \\
\left(\mathrm{mm}^{2}\right)\end{array}$ & SFR (\%) & $\begin{array}{l}\text { Overall } \\
\text { complications (\%) }\end{array}$ & $\begin{array}{l}\text { Bleeding requiring } \\
\text { transfusion or } \\
\text { intervention (\%) }\end{array}$ \\
\hline $\begin{array}{l}\text { Kyriazis et } \\
\text { al. }\end{array}$ & 2017 & 137 pts (NP) & 30 & $210 \pm 199$ & 84.6 & 10.20 & 3.6 \\
\hline $\begin{array}{l}\text { Kallidonis et } \\
\text { al. }\end{array}$ & 2017 & $\begin{array}{l}27 \text { pts (P) } \\
28 \text { pts (NP) }\end{array}$ & $\begin{array}{l}30 \\
30\end{array}$ & $\begin{array}{l}14.3 \pm 5.8 \\
14.9 \pm 6.6\end{array}$ & $\begin{array}{l}\text { ND } \\
\text { ND }\end{array}$ & $\begin{array}{l}7.40 \\
7.14\end{array}$ & 7.4 \\
\hline $\begin{array}{l}\text { Kallidonis et } \\
\text { al. }\end{array}$ & 2021 & 32 pts (NP) & 22 & $23.5 \pm 6.6$ & 93.8 & 9.40 & 0.0 \\
\hline $\begin{array}{l}\text { Kallidonis et } \\
\text { al. }\end{array}$ & 2020 & $\begin{array}{l}53 \text { pts (NP } \\
\text { with staghorn } \\
\text { stones) }\end{array}$ & 30 & $60.1 \pm 16.1$ & 81.1 & 20.70 & 3.2 \\
\hline Tahra et al. ${ }^{6}$ & 2020 & $\begin{array}{l}207 \text { pts (P) } \\
69 \text { pts (NP) }\end{array}$ & $\begin{array}{l}30 \\
30\end{array}$ & $\begin{array}{l}2.46 \pm 4.6 \\
2.38 \pm 5.1\end{array}$ & $\begin{array}{l}86.4 \\
85.5\end{array}$ & $\begin{array}{l}7.10 \\
7.20\end{array}$ & $\begin{array}{l}3.8 \\
1.4\end{array}$ \\
\hline
\end{tabular}

ND: no data; NP: non-papillary; P: papillary; pts: patients: SFR: stone-free rate.

The authors further investigated their hypothesis in a randomised controlled trial comparing papillary and non-papillary PCNL. ${ }^{5}$ They did not find any statistical difference in the level of haemoglobin drop, transfusion, and bleeding rates, as well as hospitalisation time between the two groups. In contrast, the operative time was significantly shorter in the non-papillary arm. ${ }^{5}$ Similar to their results, no statistically significant differences were reported in a retrospective matched-pair case-control study by Tahra et al. ${ }^{6}$ Out of 69 patients with non-papillary puncture, a blood transfusion was only required in one patient. No significant differences were reported for overall complications.

The feasibility and safety of the non-papillary approach were also investigated for mini-PCNL using $18 \mathrm{Fr}$ nephroscope with a maximal outer sheath diameter of $22 \mathrm{Fr}^{7}$ The mean haemoglobin drop in the cohort was $1.23 \pm 0.88 \mathrm{gr} / \mathrm{dL}$ and none of their patients developed severe bleeding requiring transfusion and additional intervention. The authors reported similar beneficial findings for patients harbouring staghorn stones having a mean stone size of $60.1 \pm 16.1 \mathrm{~mm}{ }^{8}$ With a 1.2 mean number of PCNL access tracts, a primary stone-free rate of $81.1 \%$ was documented. The mean haemoglobin loss was $1.6 \pm 1.86 \mathrm{gr} / \mathrm{dL}$ and one patient required a blood transfusion.
Table 1 summarises the outcomes of all studies performed on non-papillary PCNL.

In general, PCNL punctures are mostly accomplished under ultrasound, fluoroscopic, and endoscopic guidance. Fluoroscopic approaches are the most utilised techniques, and interpretation of the 3D renal anatomy on 2D images can sometimes require great effort. ${ }^{9}$ The latter can be more challenging for novice specialists following the papillary approach due to the reduced area suitable for puncture. The authors believe that their proposed technique of non-papillary approach eases the orientation, as the puncture is directed toward the stone at the most convenient site for stone lithotripsy.

In the authors' hands, the non-papillary approach was associated with additional benefits. Having straight access to the renal pelvis allows uncomplicated passage of the guide-wire down the ureter, increasing the safety of subsequent tract dilation. Moreover, over-passing the calyces opens room for better manipulation and increases the efficiency of lithotripsy from a single PCNL tract. In such a way, stones located in the pelvis and different renal calyces can be treated simultaneously. The straight access to the renal pelvis also eases the manipulation and successful extraction of stones from the proximal 
ureter. Although the pelvis is aimed for with the non-papillary approach, the rate of postoperative urine leakage and issues of tract healing are not observed. The authors' radiological studies demonstrated that the punctures to the infundibula and renal pelvises had a similar area of approach compared to the punctures to mid-calyceal fornices. ${ }^{10}$

The authors acknowledge the criticism that the non-papillary approach is not the standard technique and more research in this field is required. Nevertheless, considering the reported results and aforementioned benefits of non- papillary puncture, the authors can propose it as a safe and effective approach for PCNL tract establishment.

\section{CONCLUSION}

Kidney puncture and access tract establishment are detrimental steps of the PCNL procedure. The papillary puncture was historically considered a safe approach. In recent years, a non-papillary puncture approach was introduced and evaluated. The initial studies prove its feasibility and effectiveness for the treatment of renal stones with standard and mini-PCNL techniques.

\section{References}

1. Kamphuis GM et al. Lessons learned from the CROES percutaneous nephrolithotomy global study. World J Urol. 2015;33(2):223-33.

2. Kallidonis $\mathbf{P}$ et al. Minimally invasive percutaneous nephrolithotomy (PCNL): techniques and outcomes. Turk J Urol. 2020;46(Suppl 1):S58-63.

3. Sampaio FJ, Aragao AH. Anatomical relationship between the intrarenal arteries and the kidney collecting system. J Urol. 1990;143(4):679-81.

4. Kyriazis I et al. Challenging the wisdom of puncture at the calyceal fornix in percutaneous nephrolithotripsy: feasibility and safety study with 137 patients operated via a non-calyceal percutaneous track. World J Urol. 2017;35(5):795-801.

5. Kallidonis P et al. Papillary vs nonpapillary puncture in percutaneous nephrolithotomy: a prospective randomized trial. $J$ Endourol. 2017;31(Suppl 1):S4-9.

6. Tahra A et al. Papillary vs nonpapillary access during percutaneous nephrolithotomy: retrospective, match-paired case-control study Arch Ital Urol Androl. 2020;92(1):502.

7. Kallidonis $P$ et al. Non papillary mini-percutaneous nephrolithotomy: early experience. World J Urol. 2021;39(4):1241-6.
8. Kallidonis P et al. Non-papillary percutaneous nephrolithotomy for treatment of staghorn stones. Minerva Urol Nefrol. 2020;DOI:10.23736/ S0393-2249.20.04124-7.

9. Kyriazis I et al. European Section of Urotechnology educational video on fluoroscopic-guided puncture in percutaneous nephrolithotomy: all techniques step by step. BJU Int. 2017;120(5):739-41.

10. Kallidonis P et al. Percutaneous nephrolithotomy puncture and tract dilation: evidence on the safety of approaches to the infundibulum of the middle renal calyx. Urology. 2017;107:43-8. 